\title{
Bootstrapping a Theory of Thinking and Learning
}

\section{A Response to Ton Jörg's Programmatic View}

\author{
M. JAYNE FLEENER \\ Louisiana State University
}

Ton Jörg's paper provides openings for conversations about the complex and dynamic relationships among teaching, learning, and the curriculum. His problematizing of thinking shapes the conversation by refocusing the teaching-learning-curriculum dynamic on the practical matter of "the complex way learning manifests itself in the practice of education" (Jorg, this issue, p. 2). By offering a perspective of learning based on interaction, Jörg's paper tackles a set of classical challenges going back as far as the philosophical debates among followers of Heraclitus, Parmenides, Democritus, and Plato, namely the nature of knowing and reality. In my response to and in conversation with Jörg's paper, I will reveal my own struggles with a vision of a dynamic, relational curriculum.

\section{Searching for a Geometry of Relationship}

My own struggles with the relationships among teaching, learning, and the curriculum go back over twenty years when, as a beginning teacher and failed philosopher/logician, I was reflecting on Alfred North Whitehead's notion of relationship as it connected to my teaching. Although not then available to me, I have since gained access to material related to Whitehead's lecture on "The Relational Theory of Space," a lecture in which Whitehead attempted his own geometry of relationship. Whitehead's efforts to address the challenges of scientific rationality and fragmentation of thought and experience 
utilized "the data and theories of contemporary science to argue for the replacement of the mechanistic by a revised teleological paradigm.... [T]his contemporary form of teleological explanation tends towards pluralism, stressing finite, interacting centers of purposive activity" (Lucas, 1983, p. 9)

I was intrigued in the early years of my teaching and since by a notion of a geometry of relationship as I came to understand my students not as objects upon which my emerging expert skills as a mathematics teacher could operate, but as complex sets of complicated interactions. How could I encourage their budding relationships with mathematics? How could I, through our classroom relationships and interactions, support their current and future learning of mathematics? How could I, as they developed their relationship with mathematics, encourage them to experience their world in mathematical ways?

According to his biographer Victor Lowe (1985), Whitehead had attempted a geometry of relationship as the fourth book of Principia Mathematica, co-authored with Bertrand Russell. His subsequent paper on "The Relational Theory of Space (RTS)," was presented six years later to the First Congress on Mathematical Philosophy in Paris in 1914 (Hurley, 1979). As a logician, I was intrigued by what later became Whitehead's method of extensive abstraction, but as a teacher, I was more enamored by the very practical problem of bringing abstract mathematics alive for my students. As described by Whitehead in RTS (Hurley, 1979):

The fundamental order of ideas is first a world of things in relation; then the space whose fundamental entities are defined by means of those relations and whose properties are deduced from the nature of those relations. (RTS, 40, emphasis added)

Whitehead's relational theory has parallels with Poincaré's representative space (Hurley, 1979) and thus serves as a bridge for a logic of relationship and a logic of meaning whereby language representation of concepts is separated from the ontological claims of "reality" with a capitol "R."

In his treatment of apparent space Whitehead is concerned with establishing a

link between levels of experience - not a link between the content of experience and some extramental realm. This same subjectivist orientation extends to his treatment of physical space. Whitehead characterizes the physical world as a "hypothetical logical construction" (RTS, 35), and physical space, far from being a receptacle for "things in themselves," is a space populated by theoretical constructs (Hurley, 1979).

Emerging at the time of my wonderings about students' developing relationships with mathematics and my own search for a geometry of relationship was the new mathematics of chaos. Chaos mathematics further complicated my thinking and confirmed, at least in my mind, the possibility of a geometry of relationship. By redefining dimensionality as a function of self-similarity and process, fractal geometry became a measure for many of life's recurring patterns. From pineapples to brains, cauliflower to societies, fractal geometry became a mathematics of life and living. Fractal geometry seemed to capture the very essence of relationship through recursive dynamics and growth; biological and social systems could become understood from the perspective of emergent and self-similarity characteristics. 


\section{Bootstrapping Theory}

The difficulty of theory-building, however, is the slippery slope of both avoiding the concept-creep of existing theory, including the confusion of using words and ideas that have theory-laden meanings, and operating without any foundation upon which to build a new theory, signifying a break with previous thinking. This is the challenge Jörg assumes as he explores the complicated relationships among learning and development, teaching and learning, and curriculum and schooling. As Jörg describes:

[L]earning and development through interaction may thus be viewed as a way of cocreating ourselves within a web of reciprocal relationship with the other. This cocreation may be described as a complex of self-generative, self-sustaining processes of mutual "bootstrapping." (Jörg, this issue, p. 1)

The metaphor of "bootstrapping" is an appropriate one to describe the complicated process of relationships within living systems and self-reference within theory-building. The original use of the bootstrap metaphor emerged in the $1880 \mathrm{~s}^{1}$ to describe a selfsustaining process, as in one picking themselves up by their own bootstraps. The process of "booting" a computer, developed in the 1950's enacted the bootstrap metaphor to create a method by which information could efficiently be utilized. Rather than writing complicated start-up codes for initializing a computer, early computer scientists developed a process through computer programming that allowed the computer to initiate processes to seek other processes in order to adaptively and efficiently evolve the startup process. This perspective of booting likewise informed evolutionary biologists to develop new understandings of how, from the simple merging of two cells, the complexity of the human fetus is achieved.

Jörg utilizes the "bootstrapping" metaphor to make sense of learning as a selfsustaining, emergent process. He likewise uses boostrapping to create a perspective of a theory of learning which overcomes the myopic perspective of scientistic efforts to articulate foundations upon which theories are built:

We should take what Giambattista Vico (1668-1744) taught us about how science operates seriously. In his writings about the science of Descartes and others at the beginning of the eighteenth century, Vico made a plea for opening our eyes and seeing how performing science with the human mind is like operating on the eye which cannot view itself (Vico, 1744). This is similar to the mind operating on its own rhetoric. A rhetoric which seems generated by its inherent blind spots and myopia, and which demonstrates an imprisonment of meaning (Jörg, this issue, p. 2).

This myopia prevents us, according to Jörg, from developing a theory of learning which avoids the objectification of the learner and the reification of ideas. Creating understandings of learning as process and learners in relationship, Jörg's perspective of education utilizes and extends ideas originally outlined by and attributed to Vygotsky to explore how "learning learns itself" (Jörg, this issue, p. 3). While issue may be taken with regard to interpretations of and attributions to Vygotsky for a vision of education

\footnotetext{
${ }^{1}$ http://en.wikipedia.org/wiki/Bootstrap
} 
based on principles of acceleration and nonlinearity, Jörg's use of Vygotsky as the bootstrapping "seed" for a theory of learning which addresses the complexity of (relations of) learning are generative for opening the conversation pertaining to a "new science" of education:

We should put an end to an educational system which is so "geared to generate predictable citizens" and stop the "trivialization of our children" (Von Foerster, 1993, p. 196)....This new way of thinking about education is a way of making education more humanistic....It is fully in line with Vygotsky's ideas and corresponds with his famous adage: "It is through others that we develop ourselves." (Jörg, this issue, p. 4)

While I cannot, nor would I find it fruitful, to take issue with Jörg's use of Vygotsky as the interpretive seed for his bootstrapped theory of learning, I find resonance of my own relational curriculum dynamics wonderings with his efforts to disrupt traditional interpretations of the educational enterprise. For me, as relational logic and chaos mathematics create the metaphors if not the techniques by which we may develop a relational approach to understanding teaching, learning and the curriculum, the challenges Jörg presents serve to disrupt the dehumanizing approaches to teaching and learning, curriculum and schooling dominating schools today with implications and possibilities for "complexifying" the school-learning environment.

\section{Relational Complexity for Teaching and Learning}

The method of "complexifying" the school-learning environment is illusive, exhibiting its own "bootstrapping" limitations. A methodless-method sounds disingenuous and is not at all helpful to those who buy in to Jörg's vision, as I do, of a relational, interactive, dynamic curriculum to support complex learning. The ordering of the curriculum, as described by Doll (2005), has evolved over the past several hundred years in the West to entail methodical accretion of knowledge through mastery of basic facts. The implied understanding of learners is that difficult or complex tasks or concepts are best approached by breaking down the complex into smaller, logical units. Mathematics instruction is perhaps the sine qua non of curricular fragmentation and hierarchical ordering whereby we organize instruction by breaking down concepts and disciplines into their smaller, more manageable skills and techniques. Before we teach algebra, according to this perspective, students must have mastered basic arithmetic and number relations. Before we can understand fractions, we must understand operations on whole numbers. And so forth.

In addition to the connections made with Mainzer's (2004) computational and theoretical approaches to thinking in complexity, studies on brain complexity and processing support Jörg's appeal to "rethink our theory and practice of learning and education"; suggesting learning may not occur as the linear accrual of information, and that complex problem solving and other complex learning behaviors may occur not as the end result of basic understandings, but may be a function of an individual's ability to make connections across a variety of intellectual and experiential domains. In a weekly blog on brain-based research, the Eide Neurolearning Blog, Drs. Fernette and Brock Eide 
offer a synthesis of cross-disciplinary research studies on learning. Many of the studies cited use functional Magnetic Resonance Imaging (fMRI) technologies to qualify differences in reasoning and thinking processes. In one study of complex reasoning reported on their blog, findings challenge the notion of the expert reasoner who, only through mastery of basic concepts, can solve difficult problems. The findings of this research suggest that "complex thinkers tend to be transdisciplinary ... their thinking is more pattern-related and iterative rather than logically related in a causal chain." 2 They suggest that children, very early on, are capable of complex thinking and creativity through transdisciplinary connections and emergent processes. These findings suggest and support crossing traditional disciplinary boundaries for opening spaces for creative and interconnected learning.

History is replete with exemplars of innovators who have crossed disciplinary lines to make new discoveries and in the process created new ways of thinking and doing. Louis Pasteur applied knowledge of crystallography to problems of silkworms to create a new science of immunology. In mathematics, Gauss and Mandelbrot are exemplars of innovators creating the sciences of typology and fractal geometry, respectively. Gleick's books, Chaos: The Making of a New Science (1987) and Genius: The Life and Science of Richard Feynman (1992) are case studies of cross-disciplinary and transdisciplinary approaches to novelty and creativity. Waldrop's telling of the beginning of the Santa Fe Institute in the book Complexity: The Emerging Science at the Edge of Order and Chaos (1993) tells the story of how conversations across disciplines, particularly economics and quantum physics, led to new understandings of complex adaptive systems.

Considering approaches to understanding creativity, some researchers have offered tangible findings that relational rather than analytic reasoning plays a part in complex thinking. Defining creativity as "linking ideas previously seen as unrelated" Ansburg and Hill (2003, p. 1141) explore Poincaré's notion that creativity includes the ability to selectively combine information previously considered unrelated ${ }^{3}$, to make connections and relationships in innovative and novel ways. They studied creative thinker's propensities to utilize disparate information in providing novel solutions to problems.

In answering the fundamental questions of schooling, we have lost sight of the purpose of educating to solve problems of society, to create and innovate, to perpetuate through the advancement and novelty of ideas. We owe it to our collective futures to complexify the learning environment, nurturing interdisciplinary, multidisciplinary and transdisciplinary approaches toward the connected understandings across disciplines. We have an opportunity to open up the curriculum, as advocated by Jörg, to the possibilities and potentialities of the future.

\footnotetext{
${ }^{2}$ http://eideneurolearningblog.blogspot.com/2006/05/complex-thinkers.html

${ }^{3}$ They, citing Miller, 1996, pp. 354-355 quote Poincaré as saying "Among the combinations we choose, the most fruitful are often those which are formed of elements borrowed from widely separated domains.”
} 


\section{References}

Ansburg, P.I. and Hill, K. 2003. Creative and Analytic Thinkers Differ in their Use of Attentional Resources. Personality and Individual Differences 34, 1141-1152.

Doll, W. 2005. The Culture of Method. In W.E. Doll, M.J. Fleener, D. Trueit, and J. St. Julien, Chaos, complexity, curriculum, and culture: A conversation, pp. 21-75. New York: Peter Lang.

Gleick, J. 1987. Chaos: Making a new science. New York: Penguin Books.

Gleick, J. 1992. Genius: The life and science of Richard Feynman. New York: Vintage Books.

Hurley, P.J. 1979. Russell, Poincaré, and Whitehead's 'Relational Theory of Space.' Process Studies, 9(1 \& 2), 14-21.

Lowe, V. 1985. Alfred North Whitehead: The man and his work Volumes I \& II. Baltimore, MD: The Johns Hopkins University Press.

Lucas, G. R. 1983. The genesis of modern process thought: A historical outline with bibliography. Metuchen, NJ: The Scarecrow Press, Inc. and the American Theological Library Association.

Mainzer, K. 2004. Thinking in complexity: The computational dynamics of matter, mind, and mankind. Berlin: Springer.

Waldrop, M. 1993. Complexity: The emerging science at the edge of order and chaos. New York: Simon \& Schuster.

\section{About the Author}

M. Jayne Fleener is the E.B. "Ted" Robert Professor and Dean of the College of Education at Louisiana State University. Her teaching and research at the post-secondary levels have been in the areas of philosophy, logic, computer science, mathematics, mathematics education, and curriculum theory. She has taught mathematics and computer science at the pre-collegiate level in North Carolina and mathematics education and curriculum theory at the University of Oklahoma and Louisiana State University. She has served as President of the Chaos and Complexity Theories Special Interest Group of the American Educational Research Association and has in the past and currently serves on a variety of boards and commissions in the areas of curriculum, leadership, and school change. She has numerous national and international publications including her books Curriculum Dynamics: Recreating Heart (2002) and Chaos, Complexity, Curriculum, and Culture: A Conversation (2005), (edited with W.Doll, D.Trueit, and J.St. Julien). She can be contacted at the following email address: fleener@lsu.edu.

(c) Copyright 2009. The author, M. JAYNE FLEENER, assigns to the University of Alberta and other educational and non-profit institutions a non-exclusive license to use this document for personal use and in courses of instruction provided that the article is used in full and this copyright statement is reproduced. The author also grants a non-exclusive license to the University of Alberta to publish this document in full on the World Wide Web, and for the document to be published on mirrors on the World Wide Web. Any other usage is prohibited without the express permission of the authors. 